\title{
Histologic Evidence of the "Sick Lobe" Carcinogenesis Theory and the Frequency of Intraepithelial Lesions in the Mammary Glands of Female Canines with No Clinical Signs of Neoplasia
}

\author{
Jahnier Andres Caicedo Martinez and Carlos Arturo Iregui Castro* \\ Faculty of Veterinary Medicine and Zootechnology, National University of Colombia, Bogota, Colombia
}

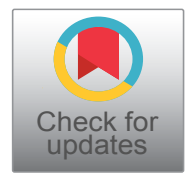

*Corresponding author: Carlos Arturo Iregui Castro, Faculty of Veterinary Medicine and Zootechnology, National University of Colombia, Bogota, Colombia, Tel: +57-1-3165000x15352,Fax: +57-1-3165000x15402, E-mail: caireguic@unal.edu.co

\begin{abstract}
Background: Intraepithelial Lesions (IELs) are focal outgrowths of the Mammary Gland (MG), some of which are considered early precursors of tumors. The early detection of IELs has improved the survival rate in women. IELs in female canines have been proposed as a comparative model of IELs in humans.

Objective: The main aim of this work was to histologically characterize IELs in the MGs of intact female dogs with no signs of mammary disease.

Methods: Biopsies of the right inguinal MG were obtained from 37 dogs under anesthesia, and the MGs from another 13 female dogs were collected at necropsy (108 total samples).

Results: MG samples obtained via biopsy did not show any IELs. Among the MGs collected at necropsy, 19 (6/13 dogs) had IELs. The most frequent IELs were adenosis (14 MGs from 4 dogs) and Carcinoma In Situ (CIS) (12 MGs from 3 dogs). Based on the results, we propose that benign and malignant complex lesions be included as IELs in canines. A main finding was that $\mathrm{CIS}$ appears to arise spontaneously in multiple lobes/lobules without any evidence of atypical IELs, that is, CIS lesions were malignant from the onset and did not appear to require any other IEL as a precursor. Conclusion: This study demonstrates that female dogs with healthy mammary glands from Bogota have a high rate of IELs in their MGs and that many of the IELs have a malignant character from the onset. Our findings support a new hypothesis for mammary gland carcinogenesis in dogs in accordance with recent theories of the origin of breast carcinomas in humans, i.e., the theory of the Sick Lobe (SL) and biological timing, highlighting the similarities between these pathologies in both species. The importance of myoepithelial cells in the early evolution of IELs is also highlighted in the present work.
\end{abstract}

\section{Keywords}

Canine, Fusiform cells, Intraepithelial lesions, Immunohistochemistry, Mammary gland, Mammary carcinoma, Myoepithelial cells

\section{Introduction}

Human mammary cancer has reached alarming levels and is considered a public health problem in Colombia and worldwide [1,2]. Mammary neoplasia is one of the most frequent types of cancer, with an incidence of 1.15 million new cases globally in 2002 , or $23 \%$ of all malignant tumors. In Latin America and the Caribbean, 300,000 women die yearly due to this disease ( 83 deaths per day) [3].

In female canines, mammary tumors are considered one of the most important cancers due to their high prevalence [4-6] and represent nearly $20 \%$ of all tumors in this species [7]. A new classification for this type of neoplasia in female canines was recently released and is very similar to that established for human females, with one important difference being the existence of complex tumors (with epithelial and myoepithelial components) in dogs. Most mammary neoplasias in canines are malignant.

Compared with canines that undergo ovariectomy, non-ovariectomized dogs have a three- to seven-fold increased risk of mammary tumors, and ovariectomy has been shown to be effective in preventing the onset of mammary tumor [8]. After two and a half years of 
age, surgery has little or no effect on tumor presentation [8]. However, some studies suggest that there may be some protection conferred by sterilization between the fourth and sixth estrus [9]. Since mammary carcinoma occurs in almost all mammalian species, an analysis and comparison of the natural occurrence of this disease in different species will improve our understanding of how this type of tumor develops in humans [10].

Factors including hormone levels, genetic predisposition, diet, environmental factors and hormone therapy have been suspected as risk factors for the development of canine mammary gland tumors, but a definitive cause(s) has not been definitively demonstrated $[4,8]$.

The "theory of the sick lobe" posits that Ductal Carcinoma In Situ (DCIS), Lobular Carcinoma In Situ (LCIS) and invasive breast cancer are diseases of the lobe in which genetic factors predispose the duct to cancer, and environmental factors promote the development of the disease. This theory suggests that individual lobes can have large areas of premalignant cells that can ultimately develop into cancer even after cancerous portions of the lobe have been removed [11].

Most invasive breast cancers are thought to evolve from early breast lesions such as atypical hyperplasia and Carcinoma In Situ (CIS) [12]. These lesions are increasingly diagnosed because of increased public awareness and routine mammographic screening [13]. Similarities in the early development of the most common carcinomatous lesions between human and canine species have recently been demonstrated. These early lesions are called Intraepithelial Lesions (IELs) [10], intraepithelial ductal and lobular neoplasia or "borderline breast diseases" [14,15]. The formation of some mammary carcinomas may involve several stages (IELs) prior to manifesting clinically, and some of these IELs are morphologic risk factors or precursors of neoplastic pathologies $[12,16]$. Because of a lack of clear criteria for diagnosing lesions and abnormal growths of the ductal or acinar epithelium with no evidence of basement membrane rupture (also called IELs) in canines [10], researchers from various regions of the world have used criteria established in human mammary pathology [17]. These criteria are based on the fact that these IELs can originate from the lobules or the ducts of the MG [16]. IELs are categorized as adenosis, sclerosing adenosis, intraductal papilloma, sclerosing papilloma, ductal hyperplasia, Atypical Ductal Hyperplasia (ADH), Ductal Carcinoma In Situ (DCIS; high, intermediate, and low grade) [17] and columnar cell lesions of the canine mammary gland [18].

This is the first of two reports documenting the early development of IELs in female canines. In this report, the epithelial and myoepithelial components of IELs are described, analyzed and compared with similar lesions in women. We propose a new hypothesis regarding the origin of these carcinomatous lesions in canines, as has re- cently been done for these lesions in humans [11,19-21]. Moreover, in this study, changes in canine myoepithelial cells similar to those in human IELs were found, and new IELs not reported in the veterinary literature are described.

\section{Materials and Methods}

\section{Animals}

A descriptive and semiquantitative study was undertaken of non-invasive and invasive intraductal and acinar epithelial lesions, denoted IELs [10,17,22]. Fifty female canines were included and represented the breeds most commonly affected by mammary tumors. The following breeds were assessed at our laboratory of Veterinary Pathology, National University of Colombia (PVL, UN): Mixed, French Poodle, German Shepherd and Labrador [23]. The animals were reproductively active (intact), had more than one estrus and had no evidence of clinical mammary disease. The physiologic status of the MG was morphologically determined according to the criteria defined by Rehm, et al. [24] Orfanou, et al. [25] and Santos, et al. [26]. The approach was used because the densities of estrogen and progesterone receptors in the mammary epithelial cells vary among the stages of the estrus cycle, which influences the activity (growth or involution) of the gland. For example, it has been described that in canine diestrus, increasing progesterone levels induce the synthesis of mammary gland Growth Hormone (GH) and Growth Hormone Receptor (GHR), which promote mammary gland proliferation [24]. Therefore, this variation must be accounted for during the histological interpretation and counting of IELs to prevent the classification of normal hyperplasia as pathological hyperplasia [27].

\section{Sampling}

The samples originated from two sources: 1) A biopsy sample from the right inguinal MG was collected under general anesthesia from individuals undergoing ovary-hysterectomy at the Zoonosis Center of Bogotá City $(Z C)$ (post-chirurgic controls were the responsibility of the $\mathrm{ZC}$ ). Biopsy was performed by incising the skin over the nipple, which is then grasped and separated bluntly from the surrounding parenchyma using mosquito hemostats or scissors. Once exposed, the mammary gland is sampled gently by cutting with scissors. Following control of hemorrhage, the skin is closed with simple interrupted sutures. The size of the MG varied between 1 and $2 \mathrm{~cm}^{3}$. 2) Visible MGs were collected from females that had been submitted to our necropsy service or to euthanasia at the ZC for reasons other than mammary disease. All of the procedures were approved by the Bioethics Unit of the Veterinary and Zootechnology School of the National University of Colombia (2011), and a procedure favored by the concept of the Professional Ethics Tribunal COMVEZCOL was utilized (2012). Chirurgic procedures were performed by qualified veterinarians. 
A single incisional biopsy was taken from the right inguinal MG from thirty-seven females undergoing ovary-hysterectomy. From the 13 cadavers ( 6 from the PVL, UN and 7 from ZC) 108 MGs were obtained. A total of 145 MG samples made up the study sample.

\section{H\&E and immunohistochemistry}

All of the samples were processed following routine histology: $3.7 \%$ formalin fixation, paraffin embedding, sectioning into 3-4 $\mu \mathrm{m}$ sections and Hematoxylin-Eosin (H\&E) staining.

Immunohistochemical analysis was performed with antibodies directed against Smooth-Muscle Actin (SMA) using a polymer-based non-avidin-biotin-peroxidase system Dako EnVision ${ }^{\mathrm{TM}}$ + Dual Link System-HRP (DakoCytomation, Glostrup, Denmark) method with a primary antibody mouse monoclonal for anti-actin, muscle-specific (HHF35) BioGenex (San Ramon, CA, USA) at a dilution of 1:50 according to the manufacturer's instructions [28].

Table 1: Type of mammary IELs and corresponding relative risks for invasive carcinoma. Atypical Ductal Hyperplasia (ADH), Atypical Lobular Hyperplasia (ALH).

\begin{tabular}{|c|c|}
\hline $\begin{array}{l}\text { Relative risk for invasive } \\
\text { carcinoma }\end{array}$ & Type of mammary IEL \\
\hline No increase & Adenosis \\
\hline \multirow{4}{*}{ Low } & Sclerosing adenosis \\
\hline & Intraductal papilloma \\
\hline & Sclerosing papilloma \\
\hline & Ductal hyperplasia \\
\hline Intermediate & ADH-ALH \\
\hline \multirow{3}{*}{ High } & Low grade \\
\hline & Intermediate \\
\hline & High grade \\
\hline
\end{tabular}

\section{Criteria for classification of IELs}

The criteria proposed by Antuofermo, et al. [10] for diagnosing IELs in canines were partially followed in this work (Table 1). These criteria were established by consulting medical pathologists, the literature regarding canine mammary pathologies [29], and recent textbooks on woman breast pathologies [11,30-32]. The classification of Ferreira, et al. [18] was followed for the columnar lesions. For carcinomas, the grade was primarily established by nuclear pleomorphism and the presence of mitosis: Low grade (1), intermediate grade (2) or high grade (3) $[10,17,32,33]$. Only one $H \& E$ slide per gland was used for counting the number of IELs. A ductal or lobular lesion was considered an IEL when it was separated from another by interlobular connective tissue.

\section{Statistical analysis}

A descriptive analysis of the frequencies of the various IELs was performed. Due to the distribution of the study population, i.e., two different populations, a separated point prevalence of the IELs was determined for each experimental group [34]. The prevalence of IELs in the biopsied canines was $0 \%(0 / 37)$, whereas the prevalence of IELs in the canines submitted to necropsy was $46.15 \%(6 / 13)$.

\section{Results}

\section{Animals}

Forty-seven of the females were mixed breed; in addition, there was one Labrador, one Poodle and one German Shepherd. IELs were found in six of 13 cadavers (five mixed breed and one German Shepherd). No IELs were observed in the animals from which biopsies were taken.

Table 2: A: Adenosis; UDH: Usual Ductal Hyperplasia; CCL: Columnar Cell Lesions; IP: Intraductal Papilloma; CH: Complex Hyperplasia; ALH: Atypical Lobular Hyperplasia; CIS: Carcinoma In Situ; CC: Complex Carcinoma; ICA: Invasive Carcinoma. Individual glands presented multifocal and multiple lesions of both the same type and of different types.

\begin{tabular}{|c|c|c|c|c|c|c|c|c|c|c|}
\hline \multirow[b]{2}{*}{ Canine subject number } & \multirow[b]{2}{*}{ MG affected } & \multicolumn{8}{|c|}{ Type of IEL } & \multirow[b]{2}{*}{ ICA } \\
\hline & & A & UDH & CCL & IP & $\mathrm{CH}$ & ALH & CIS & CC & \\
\hline 2 & A1L & 0 & 0 & 0 & 0 & 0 & 0 & 1 & 0 & 0 \\
\hline \multirow[t]{8}{*}{6} & T2L & 1 & 0 & 1 & 1 & 0 & 0 & 1 & 0 & 1 \\
\hline & A1L & 1 & 0 & 1 & 0 & 1 & 0 & 1 & 0 & 1 \\
\hline & A2L & 1 & 1 & 1 & 0 & 0 & 0 & 1 & 1 & 1 \\
\hline & IL & 1 & 0 & 0 & 1 & 0 & 0 & 1 & 1 & 1 \\
\hline & T2R & 1 & 1 & 0 & 0 & 0 & 0 & 1 & 1 & 1 \\
\hline & A1R & 1 & 0 & 1 & 0 & 0 & 0 & 1 & 1 & 1 \\
\hline & A2R & 1 & 0 & 0 & 0 & 0 & 0 & 1 & 1 & 1 \\
\hline & IR & 1 & 0 & 0 & 1 & 0 & 0 & 1 & 0 & 0 \\
\hline \multirow[t]{5}{*}{7} & A1L & 0 & 0 & 0 & 0 & 1 & 0 & 0 & 0 & 0 \\
\hline & A2L & 0 & 1 & 0 & 0 & 0 & 0 & 0 & 0 & 0 \\
\hline & T2R & 0 & 0 & 0 & 0 & 0 & 0 & 1 & 1 & 0 \\
\hline & A2R & 1 & 0 & 0 & 0 & 1 & 0 & 0 & 0 & 0 \\
\hline & IR & 1 & 0 & 0 & 1 & 1 & 0 & 0 & 0 & 0 \\
\hline \multirow[t]{2}{*}{8} & IL & 1 & 1 & 0 & 0 & 0 & 0 & 1 & 0 & 0 \\
\hline & IR & 1 & 1 & 0 & 0 & 0 & 0 & 1 & 0 & 0 \\
\hline 16 & IL & 0 & 0 & 0 & 0 & 0 & 1 & 0 & 0 & 0 \\
\hline \multirow[t]{2}{*}{22} & IL & 1 & 0 & 0 & 0 & 0 & 0 & 0 & 0 & 0 \\
\hline & IR & 1 & 0 & 0 & 0 & 0 & 0 & 0 & 0 & 0 \\
\hline Total $=57$ & & 14 & 5 & 4 & 4 & 4 & 1 & 12 & 6 & 7 \\
\hline Percentage (\%) & & 25 & 9 & 7 & 7 & 7 & 2 & 21 & 11 & 12 \\
\hline
\end{tabular}


Regarding the reproductive status of the affected animals, two were in early diestrus, one was in late diestrus (pregnant), one was in estrus, one was in early anestrus and one was in late anestrus.

Only 19 of 108 (17.6\%) sampled MGs had IELs and/ or Invasive Carcinomas (ICA) in the six females that showed any of these lesions. A total of $50 \mathrm{IELS}$ and 7 ICA were diagnosed. A total of $64 \%$ of the IELs were low risk, and the remaining $36 \%$ were high risk. However, when including the ICA, $43.8 \%$ were high risk and $56 \%$ were low risk. High-risk lesions, whether invasive or not, affected 4 (66.7\%) of the 6 females. Eighty-four percent of the affected MGs were from the inguinal and abdominal regions, whereas only $16 \%$ were from the thoracic region (Table 2).

\section{IEL morphology}

Only the frequency was investigated for IELs already described in the veterinary literature $[10,17,29,35]$.

IELs of low morphologic risk: Fourteen adenosis, five Usual Ductal Hyperplasia (UDH), four columnar lesions (all within DCIS), four intraductal papillomas and one atypical lobular hyperplasia were found; their cytology and architecture agree with the reported characteristics [10].

Complex hyperplasia and complex carcinoma, which have equivalents in mammary tumors but have not been described as IELs or hyperplasia/dysplasia in the veterinary literature, were included in this work [29].

Complex Hyperplasia (CH): Four lesions were diagnosed as $\mathrm{CH}$. These followed the classical morphology described for these lesions, i.e., proliferating epithelial and myoepithelial cells.

\section{Pre-invasive high-risk IELs and invasive carcinoma}

Carcinoma In Situ (CIS): In 12 (63\%, 12/19) MGs, two types of CIS were diagnosed: Ductal carcinoma in situ and lobular carcinoma in situ. They were counted in each gland, and the DCIS lesions were subdivided according to morphologic pattern: Cribriform, papillary, micropapillary, solid and comedo-type necrosis. Each CIS was separated by interlobular connective tissue.

In addition to the morphologic characteristics and frequency of DCIS or LCIS, the nuclear grade for each lesion was established. As shown in Table 3, $26 \%$ of $\mathrm{CIS}$ lesions had high nuclear grade and $18(42.9 \%)$ were grade 2 .

Ductal Carcinoma In Situ (DCIS) ( $\mathbf{n}=\mathbf{2 5}$ ): The term DCIS encompasses a heterogeneous group of neoplastic epithelial cells within the mammary duct system with an intact basement membrane and the presence of a myoepithelial cell layer; they do not have the ability to metastasize but possess a risk for progression to invasive cancer $[30,36,37]$. These lesions differ with regard to their mode of presentation and histopathological features. The ductal carcinoma in situ has traditionally been classified according to its architectural pattern of growth in cribriform, papillary, micropapillary, solid, and comedo carcinoma, the latter being characterized by the presence of central necrosis. Graduation is established mainly by nuclear pleomorphism and/or presence of necrosis in a system of three degrees (low grade or 1 degree, intermediate or 2 and high grade or 3) [38].

Papillary DCIS: Seven carcinomas were classified as Papillary DCIS. These carcinomas are within a dilated duct and frequently arise from one or more locations on the wall of the ductal epithelium, supported by a branching fibrovascular core. Most of the nuclear grades of these lesions were intermediate $(n=5)$ or high $(n=2)$.

Micropapillary DCIS: Eight lesions were classified as Micropapillary DCIS; within a duct, these lesions are primarily multifocal, but in contrast with the papillary DCIS, they lack a branching fibrovascular core. Most nuclear grades were low (63\%) or intermediate (25\%) (Figure 1). One of these lesions showed squamous differentiation (layers of keratin with undifferentiated cells).

Solid DCIS: Five lesions were considered as solid DCIS; among them, $40 \%$ were high nuclear grade, $40 \%$ were intermediate grade and $20 \%$ were low grade. These lesions consist of a duct filled with an uninterrupted mass of epithelial cells.

Comedo DCIS: Five lesions were diagnosed as Comedo DCIS. The nuclear grade was III in $100 \%$ of these lesions. This lesion is characterized by the presence of necrosis in the central mass of epithelial cells.

Lobular Carcinoma In Situ (LCIS): Seventeen lesions were diagnosed as LCIS. They involve the alveoli and

Table 3: Distribution of different types of DCIS and LCIS.

\begin{tabular}{|c|c|c|c|}
\hline Diagnosis & \begin{tabular}{l|} 
No. of lesions \\
(No. of + )
\end{tabular} & $\begin{array}{l}\text { No. of } \\
\text { lesions }\end{array}$ & $\begin{array}{l}\text { Nuclear } \\
\text { degree }\end{array}$ \\
\hline \multirow{3}{*}{ LCIS } & \multirow{3}{*}{$\begin{array}{l}17 \\
(2)\end{array}$} & 7 & I \\
\hline & & 9 & II \\
\hline & & 1 & III \\
\hline \multirow{3}{*}{ DCIS papillary } & \multirow{3}{*}{$\begin{array}{l}7 \\
(2)\end{array}$} & 0 & I \\
\hline & & 5 & II \\
\hline & & 2 & III \\
\hline \multirow{3}{*}{ DCIS micropapillary } & \multirow{3}{*}{$\begin{array}{l}8 \\
(2)\end{array}$} & 5 & I \\
\hline & & 2 & II \\
\hline & & 1 & III \\
\hline \multirow{3}{*}{ DCIS solid } & \multirow{3}{*}{$\begin{array}{l}5 \\
(1)\end{array}$} & 1 & I \\
\hline & & 2 & II \\
\hline & & 2 & III \\
\hline \multirow{3}{*}{$\begin{array}{l}\text { DCIS comedo-type } \\
\text { necrosis }\end{array}$} & \multirow{3}{*}{$\begin{array}{l}5 \\
(2)\end{array}$} & 0 & I \\
\hline & & 0 & II \\
\hline & & 5 & III \\
\hline
\end{tabular}

Female. 


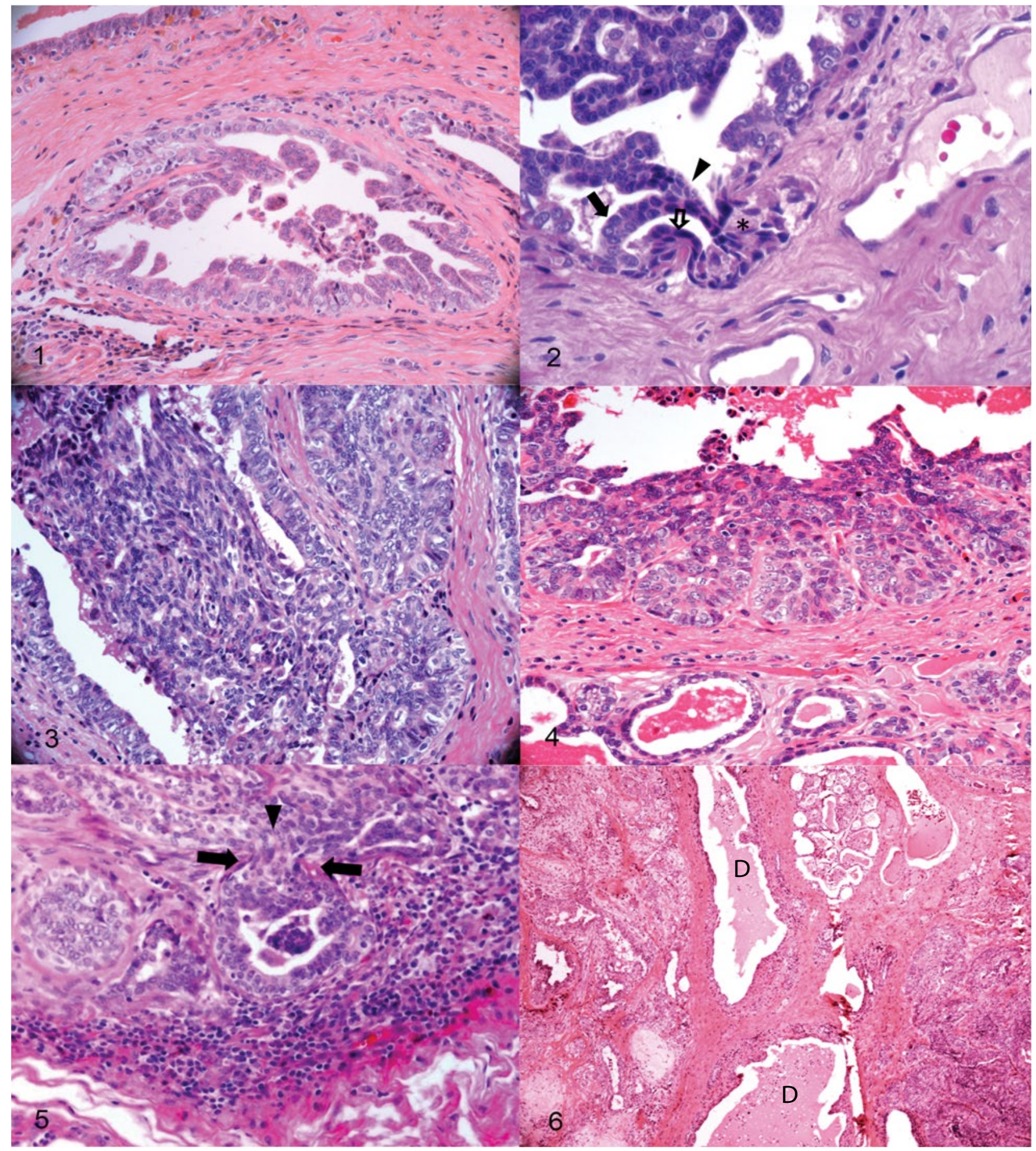

Figure 1: Mammary gland, dog, intermediate grade Micropapillary DCIS. A mild lymphocytic infiltrate is observed immediately below. H\&E 200x.

Figure 2: Mammary gland, dog. Invasive carcinoma. Two bands of neoplastic cells project into the duct's lumen (arrow), they fuse to each other (arrowhead) before returning to the duct's wall, where they break the basal membrane and invade the stroma. Some nuclei adopt a fusiform appearance (open arrow). Another band of fusiform cells accompany the invading cells at the periphery (asterisks). H\&E 400x.

Figure 3: Mammary gland, dog, High-grade DCIS. Fusiform cells project into the duct lumen. H\&E 20x.

Figure 4: Mammary gland, dog, high-grade DCIS. The uppermost layer of the epithelium adopts a fusiform aspect and appears to form a single layer joining five active proliferating projections of the epithelium; the innermost layer of cells has large nuclei with prominent nucleoli and some with loose chromatin (euchromatin). The acini at the bottom show a normal appearance. H\&E 20x.

Figure 5: Mammary gland, dog. Invasive carcinoma. The epithelial cells within a projection of a tubule adopt a fusiform appearance when they project into the stroma (arrowhead between arrows). Lymphocytic infiltrate surrounds the lesion. H\&E 400x.

Figure 6: Mammary gland, dog. Complex carcinoma on the left and LCIS on the right; they are separated only by the ducts. Different subtypes of carcinomas can arise within the same "sick lobe". H\&E 4x. 
the ductules in a lobule (i.e., they have a lobule-centric distribution) and are characterized by a proliferation of cells with typical features of carcinoma, including a higher density of cells than in normal acini, atypia and lack of polarity of the cells. They show different levels of nuclear degree and typically a lack of polarity; eccentric nuclei as well as large nucleoli were included. Distention of the ductules is common but not necessary for the diagnosis.

These lesions primarily affected the acini and terminal duct lobular unit of the MG. Most of the lesions had a nuclear grade from low to intermediate, and only one case had a high nuclear grade.

Complex carcinoma: Six lesions were considered as complex carcinoma (multifocal proliferations of malignant epithelial cells accompanied by benign myoepithelial cells). The malignant phenotype could be demonstrated only at high magnification in the epithelium.

Invasive Carcinoma (ICA): Seven lesions were included in the ICA group. The lesions were small and could still be viewed in a 40x field; they exhibited various architectonic patterns and formed ducts or solid areas and comedo-necrosis. The cells demonstrated moderate to severe pleomorphism, and those that invaded the stroma had a fusiform appearance (Figure 2). This fusiform morphology was apparent not only for invading stroma but also for cells that projected into the duct lumen (Figure 3 and Figure 4), and even some of them return to the alveolar wall (Figure 5). The nuclear pleomorphism was moderate to severe, with clumped (vesicular) chromatin and many mitoses, some of which were aberrant. Multifocal necrosis and an infiltrate of lymphocytes plasma cells and macrophages accompanied these lesions.

\section{Evidence of "sick lobe/lobule"}

The most relevant finding of this work regards the presence of DCIS or LCIS in all of the dogs with carcinomatous lesions. These lesions arise de novo in a few or many ducts or lobules simultaneously (synchronously or asynchronously) without any evidence of a precedent IEL, i.e., within or in direct contact with morphologically normal acini or ducts (Figure 6 and Figure 7). A lymphoplasmocitary and macrophage response accompanies most of these lesions (Figure 8).

\section{IHQ SMA}

Most ICA showed multifocal breaches of the nearby myoepithelial cells; however, not all demonstrated this change. Some ICA retained a complete myoepithelial layer; additionally, in some or multiple places, normal ducts or acini showed evidence of slight breaches in the myoepithelial layer (Figure 9, Figure 10 and Figure 11).

\section{Discussion}

No IELs were detected in female dogs treated at the $\mathrm{ZC}$, from which only a biopsy of the right inguinal gland was sampled. This site is reported to be the most frequent site for mammary tumors in this species. This observation is supported by the results of the necropsy group of females, in which the highest frequency of IELS was observed in the inguinal MG (Table 3). The present results suggest that incisional biopsy is unsuitable for the diagnosis or research of early lesions in canines.

Furthermore, as deduced from the morphological diversity of IELs in this work and from their multifocality within and between MGs, excisional biopsies will face the same diagnostic inaccuracies as the incisional technique. To reduce sampling error, it may be appropriate to recommend that future research utilizes live animals and clinical studies and that samples for histology are always accompanied with diagnostic images $[13,39]$.

The prevalence of IELS in necropsied females was $46.15 \%$, which is similar to that reported by Warner [40] and Mouser, et al. [17] Four (66.7\%) of the 6 necropsied individuals with IELs had at least one problematic lesion since its beginning; this percentage is notably higher than the 52\% reported by Mouser, et al. [17] Interestingly, with only one less ICA than CIS, there was a nearly even ratio $(0.87: 1)$ of these two lesions in female number 6 (Table 2). The potential implications of this finding are discussed below. If all the lesions with a malignant but non-invasive appearance and those declared overtly malignant are grouped together, the percentage reaches $44 \%$ (CIS, 21\%; Ca complexes, 11\%; ICA, 12\%), i.e., $66 \%$ of the population would be almost $50 \%$ likely to have a compromising injury from the start.

The IELs in this study occurred more frequently in abdominal and inguinal regions than in thoracic glands. This is consistent with what is known for malign and benign clinical tumors [41] and confirms the good correlation of the localization of IELs and tumors with the prevalence percentage of both groups of pathologies. Similar results were documented by Mouser, et al. [17].

We found more intermediate $(42.9 \%)$ and high-risk (26.2\%) IELs than low-risk lesions. These data are in accordance with those reported by various authors for clinically evident malignant tumors. Approximately $40 \%$ to $50 \%$ of these tumors were malignant [8]; however, our findings are in contrast with those of Mouser, et al. [17] who reported a greater percentage of low-risk than high-risk lesions. This difference between studies might be attributable to the different breeds included in each study. In Mouser, et al. [17] most of the females were coonhound and foxhound breeds, for which no high frequency of MG tumors has been documented; in our case, we selected breeds that in our experience and in international studies are considered highly susceptible to mammary neoplasia $[8,9,23]$. Our results suggest that in addition to breed, the morphology and nuclear grade of the IELs might be a prognostic factor for the development of tumors. In addition, our results are consistent with those of Antuofermo, et al. 


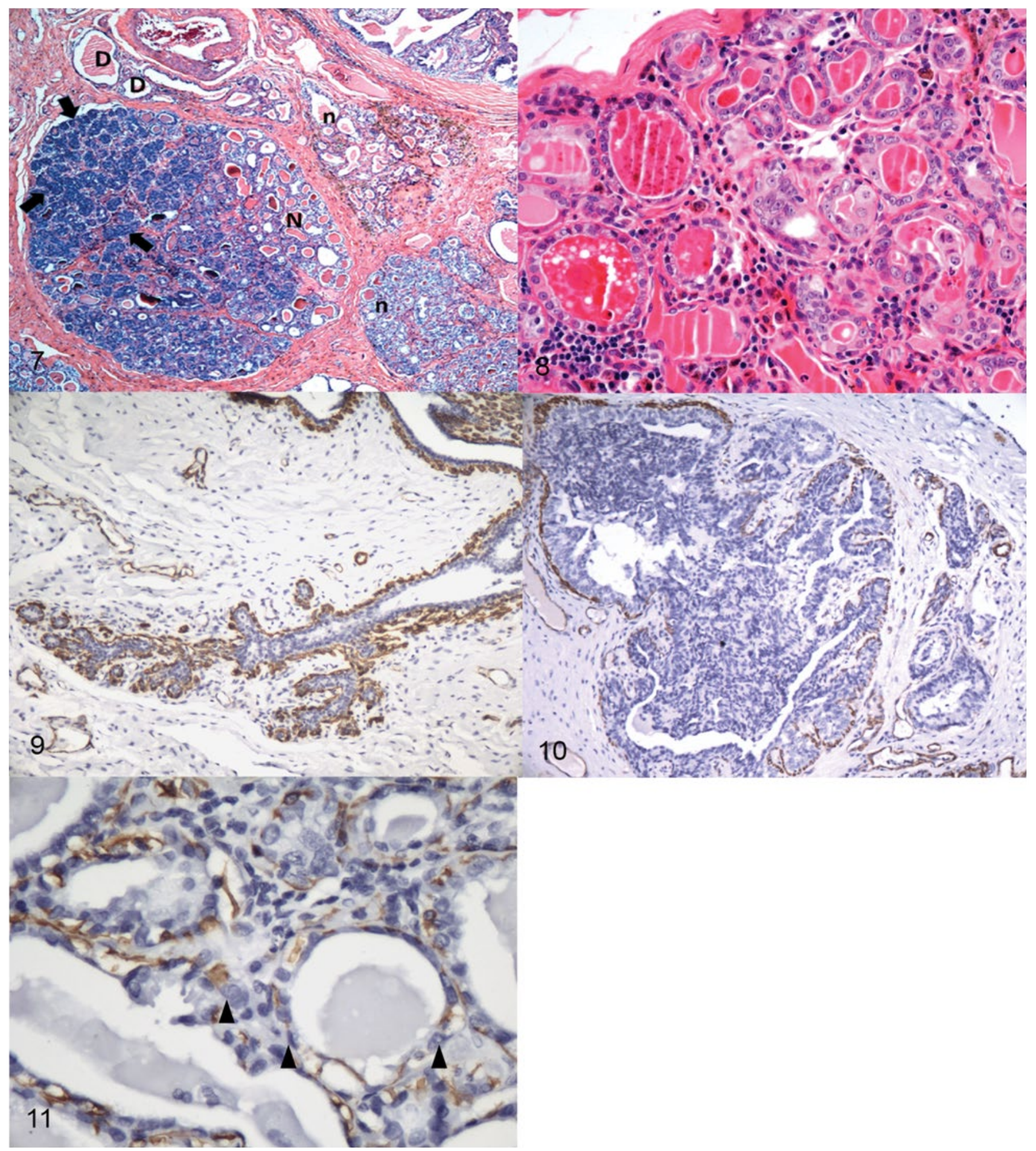

Figure 7: Mammary gland, dog, intermediate grade LCIS "sick lobe". Note higher cellular and nuclear densities (deeper basophilia) of carcinomatous acini (primarily in the uppermost left quadrant (arrows)) adjacent to some apparently normal acini $(\mathrm{N})$; other lobules with normal appearance $(n)$; at first view, there is no compromise of the intralobular ducts (D). Note the "spontaneous" origin of the carcinomatous region with no other intervening IELs. H\&E 40x.

Figure 8: Mammary gland, dog, intermediate grade LCIS, "sick-lobe". Apparently healthy acini admixed with other malignant appearing acini; no other intervening IELs are evident between the "normal" and malignant areas. Cells and nuclei at the malignant region are irregularly oriented, nuclei are more numerous per unit of area, the chromatin is very active, and prominent nucleoli are visible. Infiltrating lymphocytes are evident at the "advance front" of the lesion. H\&E 200x.

Figure 9: Mammary gland, dog. Normal myoepithelial cells surrounding the terminal duct-lobular unit. IHC, myosin-heavy chain, 100x.

Figure 10: Mammary gland, dog, papillary DCIS. Extensive areas of discontinuous myoepithelial cell layer surround and are within a papillary DCIS. IHC, myosin-heavy chain, 100x.

Figure 11: Mammary gland, dog, low grade LCIS. Multiple breaches of the myoepithelial cell layer (arrowheads). IHC, myosin-heavy chain, 400x.

[10] and Mouser, et al. [17] corroborating that an MG can bear more than one type of IEL (Table 2) and emphasizing the utility of incisional or excisional biopsies as the only diagnostic approach in clinical cases [42]. 
The susceptibility of mixed-breed females with mammary neoplasia was supported in this study. Ten individuals with this condition had the largest number of IELS, which is in contrast with other studies in which pure-bred canines appeared to be more predisposed to these pathologies [9]. A higher frequency of these neoplasms has been documented for pure breeds, such as Shih Tzu, which develop malignant mammary tumors at young ages and overexpress BRCA1, a gene involved in the carcinogenesis of mammary tumors. Maltese, Yorkshire Terrier and Poodle breeds also develop mammary cancer but do not overexpress BRCA1 [43].

There is considerable disagreement regarding the classification of human IELs $[22,27,30]$. There is even less consensus in veterinary medicine, and although IELs are reported and classified as in human medicine, few studies have thoroughly investigated these lesions in dogs or compared them with those of humans $[13,17,44]$. Additionally, with the exception of the works by Mouser, et al. [17] (in which the study animals had no clinical signs of mammary tumors) and Mohammed, et al. [13] (in which some females did not have mammary tumors), previous studies on IELs have included animals with clinical mammary tumors $[10,18]$. This complicates comparisons.

Based on our results, we suggest that the definition of IEL expression in canines should be revised, split or expanded. We propose that the following criteria be included for assessing and classifying these lesions: 1) At least two categories of IELs should be established: "low-risk" (including adenosis, UDH, ADH, papillary, and CH IELS) and "high-risk" (such as CIS IELs, which should include complex CIS because this lesion is more common in canine than human mammary carcinoma). This proposal is supported by others who claim that the lowrisk epithelial arrangements do not necessarily manifest clinically and do not always progress to cancer [10]. 2) The criteria should specify the histogenetic origin of the canine mammary epithelial lesion [45] (duct or lobule). This will enable investigations into differences regarding the pattern of invasion and prognostic value of tumor cells during tumor progression [11]. 3) The use of 'intraepithelial' means that these pathologies are independent of their immediate environment; however, as recent research demonstrates, the stroma has a more significant role in the evolution of these lesions than previously acknowledged [20,46-54]. Our own research in canines clearly shows that these pathologies are accompanied by significant (and to some extent are dependent on) changes starting in early development not only of myoepithelial cells but also their surrounding microenvironment, which includes the basal membrane, the amount of connective tissue and the infiltration of leukocytes [19,55-67].

Adenosis was the most prevalent lesion in this study (25\%). However, only one female (canine 22 ) had this as a unique lesion. In another individual (canine 6), in addition to abundant adenosis, high-risk IELs as well as ICA were present.

Mouser, et al. [17] found higher frequencies of UDH (45.4\%), DCIS (29.6\%), ADH (13\%), and complex adenoma (11.1\%) IELs than observed here; in the present study, adenosis was the most prevalent $(25 \%)$ type of IEL, and CIS (21\%), complex carcinoma (11\%) and ICA (12\%) were also frequently observed. Mouser, et al. [17] analyzed 209 lesions, with UDH lesions comprising $45.4 \%$, much higher than the $9 \%$ recorded in this study. The differences might be due to differences in the classification criteria used in the two works. In our case, the physiological stages of the canine estrus (reproductive cycle) such as proestrus, estrus, and diestrus, as proposed by Sorenmo, et al. [9] were taken into account. However, Mouser, et al. [17] used inclusion criteria of human breast pathologies and thus considered UDH when more than two cell layers were present; [38] according to those criteria, the primary criterion for classifying a lesion as UDH is several epithelial cell layers with regular proliferation within the duct lumen without any other sign of abnormal cell growth [9,24-26]. Under our criteria, this would not be considered a pathologic change.

The presence of columnar lesions in canine mammary glands is described within ICA (28.4\%), DCIS (29.8\%), benign tumors (31.4\%) and normal MGs (10.4\%). These lesions are pathologically and immunephenotypicaly similar to those in human breast [18]. In our study, all columnar lesions (7\%) were contained within $\mathrm{CIS}$; in women, the columnar injuries are considered to be markers for the presence of atypia, with a two-fold increased risk of progressing to a breast cancer [30].

The study by Mouser, et al. [17] was aimed at detecting IELs, and the animals were selected without clinical mammary signs. However, they diagnosed several "benign tumors", such as simple adenoma, complex adenoma, mixed benign tumor, basaloid adenoma, ductal papilloma and sclerosing papilloma, among which only ductal papilloma was found in the present study. We are not sure why these authors ascribed the term "benign tumors" to lesions that are not clinically manifested because that was their primary criterion for defining IELs. According to our (and others') understanding of IELs, in addition to the continuity of the basal membrane $[10,15,68]$, they should not exhibit any clinical signs.

No ADH was observed in this work, and only one ALH was observed. In contrast, Antuofermo, et al. [10] and Mouser, et al. [17] reported these injuries in 4.67 and $13 \%$ of cases, respectively. Our results suggest that unlike IELs in women (in whom ADH is considered a step in the evolution to malignant lesions), IELs in canines do not evolve from benign to malignant stages. Several findings of this study lend support to the hypothesis that high-risk lesions have a malignant character from 
the very beginning, as also reported for women by Man, et al. [20]. For example, it is not plausible that highly prevalent lesions (such as CIS, which exhibit a variable morphology) can derive from a monomorphic atypical IEL (such as $A D H$, which had a very low prevalence in this study) and are not spatially related to high-risk lesions (CIS, ICA and Complex carcinoma).

This study categorizes CIS as 1) DCIS lesions that are derived from the ducts and 2) LCIS, in which the cells preferentially originate from the lobules. The latter can originate from the acini or the intralobular ductules because both structures are indistinguishable via $H \& E$ $[2,30]$. Important carcinogenic mechanism differences have been demonstrated for both types of CIS depending on their localization [11]. For instance, the lobular carcinoma does not express E cadherin; consequently, the malignant cells do not show cohesion and adopt a plasmacytoid aspect when invading, whereas the ductal carcinoma tend to form tubules when invading [30]. Our findings demonstrate that as in women, pre-invasive lesions of the MG in canines anatomically originate from the terminal duct-lobular unit; however, the immunohistochemical profiles of $E$ cadherin and CK-34 beta $\mathrm{E} 12$ are required to confirm the 17 LCIS diagnosed in this work $[2,69]$.

No clear pattern of prevalence of the nuclear grades emerges from the 3 works that specifically analyze IELs (Mouser, et al. [17], Antuofermo, et al. [10] and this work). Nonetheless, remarkably, most CIS in this study were of intermediate (42\%) or high grade $(27 \%)$; only $5.88 \%$ of the IELs diagnosed as LCIS were grade III, whereas the same grade for DCIS had a rate of $44 \%$. It is possible that, as proposed by the theory of the "sick lobe" (see below), DCIS lesions are more malignant than LCIS lesions and consequently have a higher probability to progress to an ICA [14,21,70,71].

In female 6, there was a high coincidence between ICA and CIS (0.87:1). This finding lends support to the hypothesis that ICA in canine's progresses from lesions that have high-risk characteristics from inception, such as the DCIS grade III. A similar progression has been described for women [16].

In this study, we propose that IELs include pathologies of complex origin: Complex hyperplasia (7\%), and complex carcinoma (11\%). To our knowledge, these have not been described as such in canine IELs but have counterparts in clinically manifest neoplasia [29,72].

Female canine and human mammary carcinomas share epidemiological, clinical, biological and histological features and have been the subject of comparative research for decades $[10,17]$. However, comparative studies of these carcinomas during the first developmental stages have received less attention $[10,73,74]$. The detection of early lesions in MG has demonstrated its importance for preventing and diminishing the mor- tality of women as a result of mammary tumors. In this study, two similarities of canine IELs with the equivalent developmental stage in female breast cancer are proposed: 1) The origin of carcinomas in canines resembles that of human mammary carcinomas as described by the "sick lobe" theory [11], and 2) Consistent with human early CIS $[28,67,73,75]$, more frequent multifocal ruptures of the myoepithelial layer were observed in canine CIS.

Perhaps the most relevant finding in this study is the presence of multilobar or multilobular in situ carcinomas (Figure 6 and Figure 7) involving several nearby or distant lobes (multilobar) or a single or multiple neighbor lobules (multilobular). In some cases, multilobar carcinomas belong to one or two different morphological categories (Figure 7 and Figure 8) that occupy most of the lobe, and no evidence of a relationship with any benign lesion is observable. Those growths appear to originate spontaneously de novo in a duct or in a lobule in which some "morphologically normal" ducts or acini persist. In our opinion, this morphology is akin to what is described by the carcinogenic theory of the "sick lobe" in the human breast. This postulates that the mammary carcinoma is a ductal/lobular disease in which unconnected tumoral foci appear simultaneously or asynchronously and develop within a unique diseased lobe/lobule [11].

The sick lobe is characterized by the presence of a large number of potentially malignant cells corresponding to mutant stem or progenitor cells dispersed unevenly within the sick lobe and that might undergo malignant transformation under the influence of exogenous and endogenous oncogenic stimuli [21]. This characteristic would make the lobe/lobule more susceptible to endo- or exogenous oncogenic stimuli than lobes or lobules of the same mamma that do not bear or have a lower number of potentially malignant cells $[11,20]$. One of the most important findings in the sick lobe is that these cells are malignant from the outset [11].

The sick lobe theory is supported by histopathological studies in women reporting that the majority of breast carcinomas are multifocal and of variable size [11]. These results are supported by modern diagnostic imaging techniques in which $40 \%$ of the disease is multifocal. The multifocality and size of carcinomas are considered important prognostic factors of the biological behavior of this disease in women $[21,76]$. Our results indicate that this process also likely occurs in female dogs and that similar studies on the biological behavior of these lesions should be performed in canines. A recent, predominantly epidemiologic report that included clinical and histopathologic data from 90 female canines with 296 tumors hypothesized those malignant mammary tumors could develop from pre-existing low-risk IELs and that the malignant tumors would be the final stage [77]. Although the authors of the report described 
that within the same MG there is substantial heterogeneity and that the benign and malignant lesions are multifocal and have variable size, they did not interpret the meaning of these findings. Similarly, Mouser [17] and Sorenmo [77] also reported the multifocality and simultaneous or asynchronous character of IELs and mammary tumors but did not offer any explanations for these changes.

Several additional changes that equate with those of woman breast carcinoma were observed in this work: First, as in female carcinoma [28], we observed a significant increase in the focal interruptions of surrounding myoepithelial cells at early stages in IELs and incipient invasive mammary carcinomas; moreover, these interruptions were more frequently associated with morphologically malignant acini or ducts (Figure 10 and Figure 11). Second, the invasion signs to the stroma show that the epithelial cells adopt a fusiform appearance as in human breast carcinomas [59]. Proliferative malignant cells in ICA in this study showed a similar morphology, and although most of them projected into the duct's lumen unexpectedly, some of them appeared to return to the wall of the duct, break the basal membrane and invade the stroma (Figure 5). We are not aware of any reports of such behavior of malign epithelial cells in canine mammary carcinoma. Third, invasive cells exhibit characteristically nuclear changes associated with malignity, such as a loss of polarity, a prominent nucleolus, an irregular shape, and megakaryosis [78]. Such changes were common in malignant epithelial cells in this study. These findings suggest that the linear model of tumor progression cannot be applied in every case [79] and that these spontaneous lesions are malignant from the beginning $[19,20]$.

\section{Conclusion}

In conclusion, this study provides evidence that canine IELs presented in Bogota with significant frequency. Similarities in the morphology of these lesions with that reported in women were demonstrated. This study provides evidence that female dogs with healthy mammary glands from Bogota, have considerable numbers of IELs in their MGs and that many have a malignant character from onset. Additionally, the current classification of IELs in female dogs should be reviewed. Our findings provide evidence to propose a new hypothesis for mammary gland carcinogenesis in dogs in accordance with recent theories of the origin of breast carcinomas in humans, i.e., the theory of the SL and biological timing, highlighting the similarities in pathologies between these species. This study also provides evidence of the epithelial-mesenchymal transition of malignant cells at the invasive front of the ICA. The relevance of myoepithelial cells during the early development of IELs and ICA in canines was also demonstrated. This information argues for a method of local molecular characterization of these lesions in canines for comparative studies of canines and women.

\section{Acknowledgements}

We thank the Veterinary Pathobiology Group, Leonardo and Gilberto, for their tireless assistance.

\section{Ethical Statement}

This study was approved by the Institutional Animal Care and Use Committee of the Faculty of Veterinary Medicine and Zootechnology, National University of Colombia, Bogota.

\section{References}

1. Parkin DM, Bray F, Ferlay J, Pisani P (2005) Global cancer statistics, 2002. CA Cancer J Clin 55: 74-108.

2. Ressel L, Millanta F, Poli A (2011) Canine invasive lobular carcinoma of the mammary gland: Morphological and immunohistochemical characterizations of three cases. $J$ Comp Pathol 144: 303-307.

3. Robles S, Galanis E (2002) Breast cancer in Latin America and the Caribbean. Rev Panam Salud Publica 11: 178-185.

4. Klopfleisch R, von Euler H, Sarli G, Pinho SS, Gartner F, et al. (2011) Molecular carcinogenesis of canine mammary tumors: News from an old disease. Vet Pathol 48: 98-116.

5. José C Oliveira Filho, Glaucia D Kommers, Eduardo K Masuda, Brenda MFPP Marques, Rafael A Fighera, et al. (2010) Retrospective study of 1,647 mammary gland tumors in dogs. Pesq Vet Bras 30: 177-185.

6. Queiroga FL, Pérez-Alenza MD, Silvan G, Peña L, Lopes C, et al. (2005) Role of steroid hormones and prolactin in canine mammary cancer. J Steroid Biochem Mol Biol 94: 181-187.

7. Misdorp W (2002) Tumors of the mammary gland. In: Meuten DJ, Tumors in Domestic Animals. (4 ${ }^{\text {th }}$ edn), lowa State Press, Ames, lowa, USA, 575-606.

8. Sorenmo K (2003) Canine mammary gland tumors. Vet Clin North Am Small Anim Pract 33: 573-596.

9. Sorenmo KU, Rasotto R, Zappulli V, Goldschmidt $\mathrm{MH}$ (2011) Development, anatomy, histology, lymphatic drainage, clinical features, and cell differentiation markers of canine mammary gland neoplasms. Vet Pathol 48: 85-97.

10. Antuofermo E, Miller MA, Pirino S, Xie J, Badve S, et al. (2007) Spontaneous mammary intraepithelial lesions in dogs - A model of breast cancer. Cancer Epidemiol Biomarkers Prev 16: 2247-2256.

11. Tot T (2011) Subgross morphology, the sick lobe hypothesis, and the success of breast conservation. Int $\mathrm{J}$ Breast Cancer 2011: 634021.

12. Grizzle WE, Srivastava S, Manne U (2010) The biology of incipient, pre-invasive or intraepithelial neoplasia. Cancer Biomark 9: 21-39.

13. Mohammed SI, Meloni GB, Pinna Parpaglia ML, Marras V, Burrai GP, et al. (2011) Mammography and ultrasound imaging of preinvasive and invasive canine spontaneous mammary cancer and their similarities to human breast cancer. Cancer Prev Res (Phila) 4: 1790-1798.

14. Galimberti V, Monti S, Mastropasqua MG (2013) DCIS and LCIS are confusing and outdated terms. They should be abandoned in favor of Ductal Intraepithelial Neoplasia (DIN) and Lobular Intraepithelial Neoplasia (LIN). Breast 22: $431-435$

15. Masood S (2010) Is it time to retire the term of "in situ carcinoma" and use the term of "borderline breast disease?". Breast J 16: 571-572. 
16. Lopez-Garcia MA, Geyer FC, Lacroix-Triki M, Marchió C, Reis-Filho JS (2010) Breast cancer precursors revisited: Molecular features and progression pathways. Histopathology 57 : 171-192.

17. Mouser P, Miller MA, Antuofermo E, Badve SS, Mohammed SI (2010) Prevalence and classification of spontaneous mammary intraepithelial lesions in dogs without clinical mammary disease. Vet Pathol 47: 275-284.

18. Ferreira E, Gobbi H, Saraiva BS, Cassali GD (2010) Columnar cell lesions of the canine mammary gland: Pathological features and immunophenotypic analysis. BMC Cancer 10: 61.

19. Man YG, Nieburgs HE (2006) A subset of cell clusters with malignant features in morphologically normal-appearing and hyperplastic tissues. Cancer Detect Prev 30: 239-247.

20. Man Y, Grinkemeyer M, Izadjoo M, Stojadinovic A (2011) Malignant transformation and stromal invasion from normal or hyperplastic tissues: True or False? J Cancer 2: 413-424.

21. Tot $T$ (2009) The metastatic capacity of multifocal breast carcinomas: Extensive tumors versus tumors of limited extent. Hum Pathol 40: 199-205.

22. Costarelli L, Campagna D, Mauri M, Fortunato L (2012) Intraductal proliferative lesions of the breast-terminology and biology matter: Premalignant lesions or preinvasive cancer? Int J Surg Oncol 2012: 501904.

23. Caicedo JA, Iregui CA, Cabarcas ME, Acosta BJ (2012) Comparative study of the frequency of mammary tumors by sex, age and histological type in dogs and humans in anatomical pathology laboratories of the National University of Colombia in Bogotá. Revista Colombiana de Ciencia Animal 5: 37-46.

24. Rehm S, Stanislaus DJ, Williams AM (2007) Estrous cycle-dependent histology and review of sex steroid receptor expression in dog reproductive tissues and mammary gland and associated hormone levels. Birth Defects Res B Dev Reprod Toxicol 80: 233-245.

25. Orfanou DC, Pourlis A, Ververidis HN, Mavrogianni VS, Taitzoglou IA, et al. (2010) Histological features in the mammary glands of female dogs throughout lactation. Anat Histol Embryol 39: 473-478.

26. Santos M, Marcos R, Faustino AM (2010) Histological study of canine mammary gland during the oestrous cycle. Reprod Domest Anim 45: e146-e154.

27. Masood S, Rosa M (2011) Borderline breast lesions: Diagnostic challenges and clinical implications. Adv Anat Pathol 18: 190-198.

28. Yousefi M, Mattu R, Gao C, Man YG (2005) Mammary ducts with and without focal myoepithelial cell layer disruptions show a different frequency of white blood cell infiltration and growth pattern: Implications for tumor progression and invasion. Appl Immunohistochem Mol Morphol 13: 30-37.

29. Goldschmidt M, Pena L, Rasotto R, Zappulli V (2011) Classification and grading of canine mammary tumors. Vet Patho 48: 117-131.

30. Dabbs DJ (2012) Breast Pathology. (1 ${ }^{\text {st }}$ edn), Elsevier Health Sciences, 412-428.

31. O'Malley FP (2011) Morphology of Ductal Carcinoma In Situ. In: O'Malley FP, Pinder SE, Mulligan AM, Breast Pathology. ( $2^{\text {nd }}$ edn), Elsevier Health Sciences.

32. Rosen PP (2009) Papilloma and related benign tumors. Rosen's Breast pathology. ( $3^{\text {rd }}$ edn), Lippincot Williams \& Wilkins edits, Philadelphia, USA, 101-108.
33. Lester SC, Bose S, Chen YY, Connolly JL, de Baca ME, et al. (2009) Protocol for the examination of specimens from patients with ductal carcinoma in situ of the breast. Arch Pathol Lab Med 133: 15-25.

34. Tapia Granados JA (1995) Prevalence measures and the incidence-prevalence ratio. Med Clin (Barc) 105: 216-218.

35. Ferreira E, Gobbi H, Saraiva BS, Cassali GD (2012) Histological and immunohistochemical identification of atypical ductal mammary hyperplasia as a preneoplastic marker in dogs. Vet Pathol 49: 322-329.

36. Jezierska-Drutel A, Rosenzweig SA, Neumann CA (2013) Role of oxidative stress and the microenvironment in breast cancer development and progression. Adv Cancer Res 119: $107-125$.

37. Kulasekara KK, Lukandu OM, Neppelberg E, Vintermyr OK, Johannessen AC, et al. (2009) Cancer progression is associated with increased expression of basement membrane proteins in three-dimensional in vitro models of human oral cancer. Arch Oral Biol 54: 924-931.

38. Rosen PP (2001) Carcinoma of the male breast. In: Rosen PP, Rosen's Breast Pathology. ( $2^{\text {nd }}$ edn), Lippincott Williams \& Wilkins edits. Philadelphia, USA, 713-728.

39. Matos AJ, Baptista CS, Gärtner MF, Rutteman GR (2012) Prognostic studies of canine and feline mammary tumours: The need for standardized procedures. Vet J 193: 24-31.

40. Warner M (1977) Response of beagle mammary dysplasias to various hormone supplements in vitro. Cancer Res 37: 2062-2067.

41. Sleeckx N, de Rooster H, Veldhuis Kroeze EJ, Van Ginneken C, Van Brantegem $L$ (2011) Canine mammary tumours, an overview. Reprod Domest Anim 46: 1112-1131.

42. Santos AA, Lopes CC, Ribeiro JR, Martins LR, Santos JC, et al. (2013) Identification of prognostic factors in canine mammary malignant tumours: A multivariable survival study. BMC Vet Res 9: 1.

43. Im KS, Kim IH, Kim NH, Lim HY, Kim JH, et al. (2013) Breed-related differences in altered BRCA1 expression, phenotype and subtype in malignant canine mammary tumors. Vet J 195: 366-372.

44. Donnay I, Devleeschouwer N, Wouters-Ballman P, Leclercq G, Verstegen J (1996) Relationship between receptors for epidermal growth factor and steroid hormones in normal, dysplastic and neoplastic canine mammary tissues. Res Vet Sci 60: 251-254.

45. Benjamin SA, Lee AC, Saunders WJ (1999) Classification and behavior of canine mammary epithelial neoplasms based on life-span observations in beagles. Vet Pathol 36: 423-436.

46. Abbas O, Mahalingam M (2011) Desmoplasia: Not always a bad thing. Histopathology 58: 643-659.

47. Allen M, Jones LJ (2011) Jekyll and Hyde: The role of the microenvironment on the progression of cancer. J Pathol 223: $162-176$

48. Barsky SH, Karlin NJ (2005) Myoepithelial cells: Autocrine and paracrine suppressors of breast cancer progression. $\mathrm{J}$ Mammary Gland Biol Neoplasia 10: 249-260.

49. Cox TR, Erler JT (2011) Remodeling and homeostasis of the extracellular matrix: Implications for fibrotic diseases and cancer. Dis Model Mech 4: 165-178.

50. Davies JA (2001) Extracellular Matrix. Encyclopedia of Life Sciences. Nature Publishing Group, 1-7.

51. Elenbaas B, Weinberg RA (2001) Heterotypic signaling between epithelial tumor cells and fibroblasts in carcinoma formation. Exp Cell Res 264: 169-184. 
52. Fata JE, Werb Z, Bissell MJ (2004) Regulation of mammary gland branching morphogenesis by the extracellular matrix and its remodeling enzymes. Breast Cancer Res 6: 1-11.

53. Kass L, Erler JT, Dembo M, Weaver VM (2007) Mammary epithelial cell: Influence of extracellular matrix composition and organization during development and tumorigenesis. Int J Biochem Cell Biol 39: 1987-1994.

54. Yoshimura H, Michishita M, Ohkusu-Tsukada K, Takahashi $\mathrm{K}$ (2011) Increased presence of stromal myofibroblasts and tenascin- $C$ with malignant progression in canine mammary tumors. Vet Pathol 48: 313-321.

55. Benazzi C, Sarli G, Galeotti M, Marcato PS (1993) Basement membrane components in mammary tumours of the dog and cat. J Comp Pathol 109: 241-252.

56. Bissell MJ, Radisky DC, Rizki A, Weaver VM, Petersen OW (2002) The organizing principle: Microenvironmental influences in the normal and malignant breast. Differentiation 70: $537-546$.

57. Boudreau A, van't Veer LJ, Bissell MJ (2012) An "elite hacker": Breast tumors exploit the normal microenvironment program to instruct their progression and biological diversity. Cell Adh Migr 6: 236-248.

58. Caicedo JA, Martinez N, Iregui C (2015) Stromal changes within in situ carcinoma and early invasive carcinomas in mammary gland of female dogs without clinical signs of mammary tumor: Histopathologic study. ACVP/ASVCP/ STP Annual Meeting, Minneapolis, USA.

59. Chen QK, Lee K, Radisky DC, Nelson CM (2013) Extracellular matrix proteins regulate epithelial-mesenchymal transition in mammary epithelial cells. Differentiation 86: 126-132.

60. Cheung KJ, Ewald AJ (2014) Iluminating breast cancer invasion: Diverse roles for cell-cell interactions. Curr Opin Cell Biol 30: 99-111.

61. Egeblad M, Rasch MG, Weaver VM (2010) Dynamic interplay between the collagen scaffold and tumor evolution. Curr Opin Cell Biol 22: 697-706.

62. Estrela-Lima A, Araújo MS, Costa-Neto JM, Teixeira-Carvalho A, Barrouin-Melo SM, et al. (2010) Immunophenotypic features of tumor infiltrating lymphocytes from mammary carcinomas in female dogs associated with prognostic factors and survival rates. BMC Cancer 10: 256.

63. Gisterek I, Frydecka I, Świątoniowski G, Fidler S, Kornafe $\mathrm{J}$ (2008) Tumour-infiltrating CD4 and CD8 T lymphocytes in breast cancer. Rep Pract Oncol Radiother 13: 206-209.

64. Luga V, Zhang L, Viloria-Petit AM, Ogunjimi AA, Inanlou MR, et al. (2012) Exosomes mediate stromal mobilization of autocrine Wnt-PCP signaling in breast cancer cell migration. Cell 151: $1542-1556$.

65. Man YG, Stojadinovic A, Mason J, Avital I, Bilchik A, et al. (2013) Tumor-infiltrating immune cells promoting tumor invasion and metastasis: Existing theories. J Cancer 4: 84-95.
66. Martins A, Tamaso E, Guerra J (2002) Retrospective review and systematic study of mammary tumors in dogs and characteristics of the extracellular matrix. Braz $\mathrm{J}$ Vet Res Anim Sci 39: 38-42.

67. Polyak K, Hu M (2005) Do myoepithelial cells hold the key for breast tumor progression? J Mammary Gland Biol Neoplasia 10: 231-247.

68. Tanner K (2012) Regulation of the basement membrane by epithelia generated forces. Phys Biol 9: 065003.

69. Turashvili G, Bouchal J, Ehrmann J, Fridman E, Skarda J, et al. (2007) Novel immunohistochemical markers for the differentiation of lobular and ductal invasive breast carcinomas. Biomed Pap Med Fac Univ Palacky Olomouc Czech Repub 151: 59-64.

70. Korhonen T, Kuukasjärvi T, Huhtala H, Alarmo EL, Holli K, et al. (2013) The impact of lobular and ductal breast cancer histology on the metastatic behavior and long term survival of breast cancer patients. Breast 22: 1119-1124.

71. Topps A, Clay V, Absar M, Howe M, Lim Y, et al. (2014) The sensitivity of pre-operative axillary staging in breast cancer: Comparison of invasive lobular and ductal carcinoma. Eur J Surg Oncol 40: 813-817.

72. Misdorp W, Else RW, Hellmen E (1999) Histologic classification of mammary tumors of the dog and cat. Armed Force Institute of Pathology, World Health Organization, Washington, DC, 7.

73. Cadieu E, Ostrander EA (2007) Canine genetics offers new mechanisms for the study of human cancer. Cancer Epidemiol Biomarkers Prev 16: 2181-2183.

74. Uva P, Aurisicchio L, Watters J, Loboda A, Kulkarni A, et al. (2009) Comparative expression pathway analysis of human and canine mammary tumors. BMC Genomics 10: 135.

75. Gudjonsson T, Rønnov-Jessen L, Villadsen R, Rank F, Bissell MJ, et al. (2002) Normal and tumor-derived myoepithelial cells differ in their ability to interact with luminal breast epithelial cells for polarity and basement membrane deposition. J Cell Sci 115: 39-50.

76. Videira M, Reis RL, Brito MA (2014) Deconstructing breast cancer cell biology and the mechanisms of multidrug resistance. Biochim Biophys Acta 1846: 312-325.

77. Sorenmo KU, Kristiansen VM, Cofone MA, Shofer FS, Breen AM, et al. (2009) Canine mammary gland tumours; A histological continuum from benign to malignant; clinical and histopathological evidence. Vet Comp Oncol 7: 162-172.

78. Sgroi DC (2010) Preinvasive breast cancer. Annu Rev Pathol 5: 193-221.

79. Cichon MA, Degnim AC, Visscher DW, Radisky DC (2010) Microenvironmental influences that drive progression from benign breast disease to invasive breast cancer. J Mammary Gland Biol Neoplasia 15: 389-397. 